\title{
Advanced and Applied Remote Sensing of Environmental Conditions
}

\section{Introduction}

"Remote sensing" is a general term for monitoring techniques that collect information without being in physical contact with the object of study. Overhead imagery from aircraft and satellite sensors provides the most common form of remotely sensed data and records the interaction of electromagnetic energy (usually visible light) with matter, such as the Earth's surface (fig. 1).

Remotely sensed data are fundamental to geographic science. The U.S. Geological Survey's (USGS) Eastern Geographic Science Center (EGSC) is currently conducting and promoting the research and development of several different aspects of remote sensing science in both the laboratory and from overhead instruments. Spectroscopy is the science of recording interactions of energy and matter and is the bench science for all remote sensing. Visible and infrared analysis in the laboratory with special instruments called spectrometers enables the transfer of this research from the laboratory to multispectral (5-15 broad bands) and hyperspectral (50-300 narrow contiguous bands) analyses from aircraft and satellite sensors. In addition, mid-wave (3-5 micrometers, $\mu \mathrm{m})$ and long-wave $(8-14 \mu \mathrm{m})$ infrared data analysis, such as attenuated total reflectance (ATR) spectral analysis, are also conducted. ATR is a special form of vibrational infrared spectroscopy that has many applications in chemistry and biology but has recently been shown to be especially diagnostic for vegetation analysis.

\section{Spectral Analysis of Vegetation and Water}

Because different materials absorb or reflect energy from different wavelengths of light in unique ways, the development of high spectral resolution sensors and analytical methods provides the ability to identify the presence or absence of target materials or conditions and to investigate the physical and chemical processes at the Earth's surface. Vegetation health and water quality are two important scientific issues that will be investigated by using hyperspectral remote sensing techniques (fig. 2).

Hyperspectral refers to a variety of remote sensing techniques that collect reflected or emitted electromagnetic energy in hundreds of narrow, contiguous bands that record the interaction of photons with the molecular structure of the material being sensed. When processed,

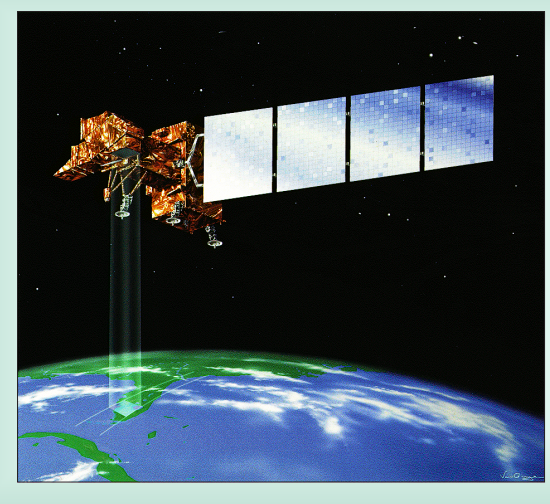

Figure 1. Artist's rendering of Landsat 7 satellite in orbit (U.S. Geological Survey, 2012a). Landsat 7 was launched on April 15, 1999. The satellite is in sun-synchronous orbit 438 miles above the Earth. The Enhanced Thematic Mapper Plus (ETM+) sensor has eight multispectral bands, including a panchromatic band and two thermal bands. The Landsat Data Continuity Mission, the follow-on to Landsat 7, was launched on February 11, 2013, and is anticipated to continue the 40 years of Landsat history of Earth observation (U.S. Geological Survey, 2012b).

the resulting plot of these energy interactions, called spectra, can be used to identify unique elements, minerals, water-quality parameters, and parameters of vegetation health and stress.

Remote sensing analyses of vegetation and water provide indicators of overall ecosystem condition, environmental stress, and landscape change at local, regional, and global scales. Advances in remote sensing imaging systems and data processing technologies have led to an increase in the use of this information to answer scientific questions related to vegetation and water issues, including the following:

- Detection of plant or water contaminants

- Identification of plant species

- Detection of plant stress

- Determination of chemical concentrations in tree canopies or leaves

- Monitoring of agricultural processes

- Correlation of plant chemistry with geology (geobotany and biogeochemistry)

- Monitoring changes in coastal and wetland areas

Combinations of techniques such as laboratory chemistry, field sampling, field spectroscopy, $\mathrm{x}$-ray fluorescence (XRF), and overhead hyperspectral imaging are being used to detect the signatures of specific contaminants and stress conditions at local to regional scales (fig. 2). Studies include the spectral analysis of heavy-metal contamination in soils and vegetation.

\section{Hyperspectral Detection of Contam- ination at Selected Superfund Sites}

A recent study done by the EGSC used hyperspectral imagery collected from satellite, aircraft, and ground-based sensors to detect the presence of hydrocarbons, metal drums, waste
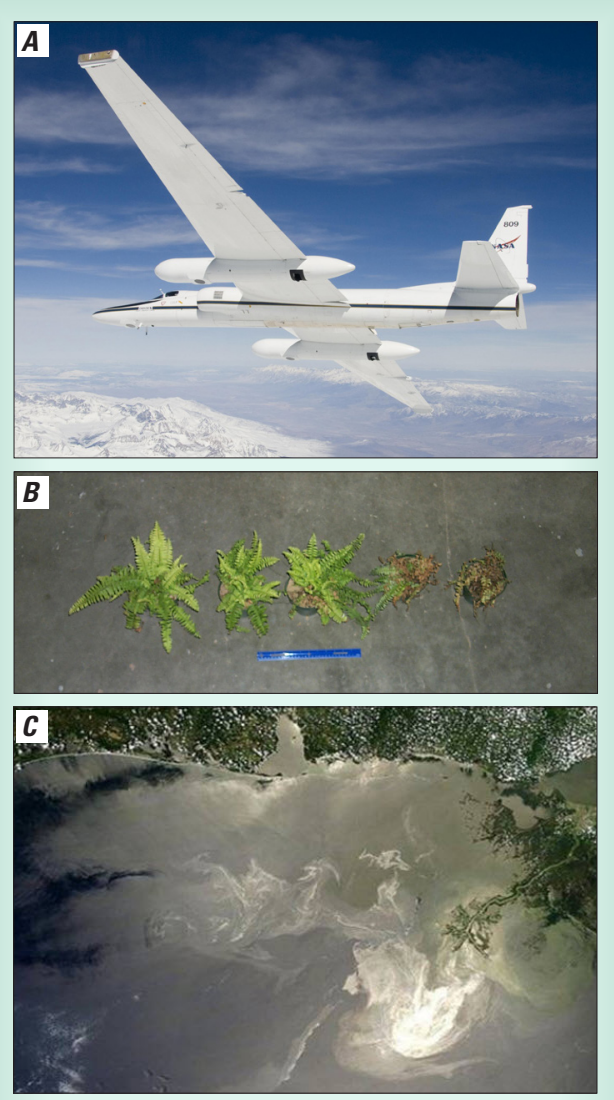

Figure 2. Multispectral and hyperspectral data collections from a variety of field and aircraft and satellite instruments are being used to analyze water and vegetation characteristics. $A$, National Aeronautics and Space Administration (NASA) ER-2 Earth resources, high-altitude aircraft (photo by Carla Thomas, NASA).

$B$, As viewed from left to right, the photo shows the effects on ferns of low to increasingly high amounts of soil arsenic concentration (Slonecker and others, 2009). C, A NASA Terra satellite image of the Deepwater Horizon oil spill, May 24, 2010. 


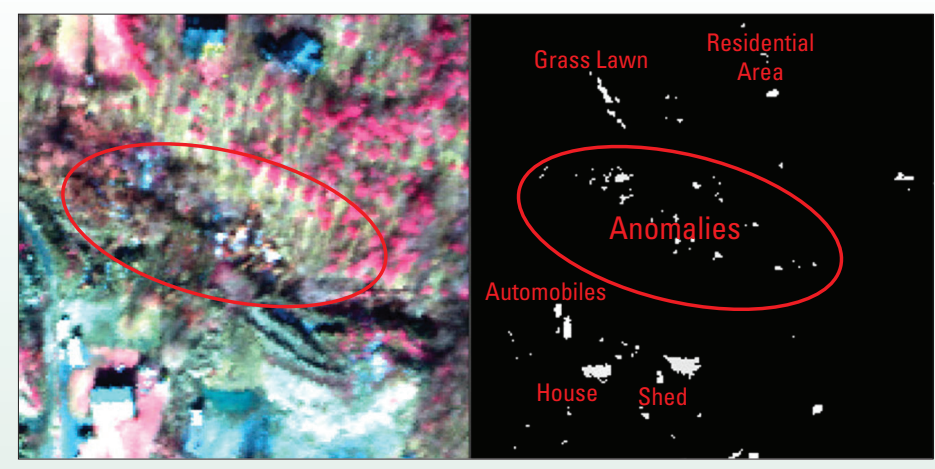

Figure 3. Two ARCHER images of a Superfund site. On the left is a standard infrared image. The circled area is the base of the landfill where, on the right, the hyperspectral anomaly detection outlines the drums and debris that were later discovered on field inspection (Slonecker and Fisher, 2011).

metal, and leachate on five different Superfund sites. Each of the five Superfund sites was a location of previous industrial activity, such as electroplating, that had closed and then undergone environmental remediation to clean up hazardous waste still present on the site. After the remediation effort, each Superfund site was tested to determine if the remediation cleanup efforts removed the heavy metals, such as zinc, from the soil (Slonecker and Fisher, 2011). The hyperspectral imagery that was collected by aircraft for each Superfund site was acquire by a sensor known as Airborne Real-time Cueing Hyperspectral Enhanced Reconnaissance (ARCHER; Space Computer Corp., 2012). ARCHER collected both visible and hyperspectral imagery over each of the five Superfund sites (fig. 3).

The ARCHER hyperspectral sensor, with 52 usable bands, a spectral range from 500 to 1100 nanometers $(\mathrm{nm})$, and a spectral resolution of $11.5 \mathrm{~nm}$, is mounted in a fixed-wing, prop-driven aircraft. Onboard the aircraft during image collection, hyperspectral detection algorithms were used to detect any anomalies on the ground such as metal bins, hydrocarbons, and heavy metals. In addition to the hyperspectral imagery collected by ARCHER, point-based field measurements of the concentration of heavy metals in the soil were taken using a hand-held device called an XRF spectrometer (fig. 4). The XRF is capable of detecting concentrations of heavy metals in concentrations as small as a few parts per million.

A laboratory hyperspectral sensor operated by the USGS that is capable of

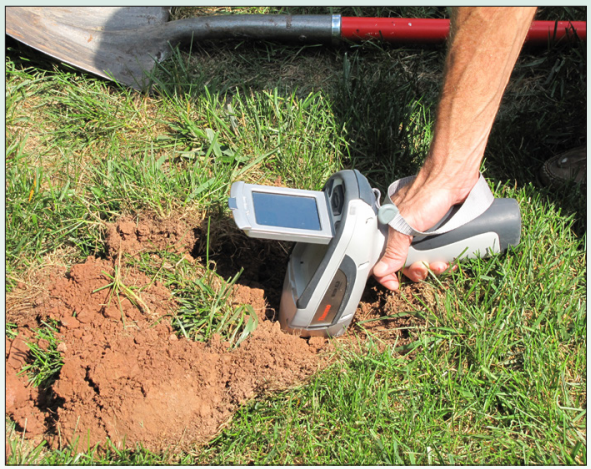

Figure 4. An x-ray fluorescence spectrometer being used to acquire metal concentrations. collecting spectral signatures in the long-wave part of the electromagnetic spectrum $(8,000$ to $14,000 \mathrm{~nm}$ ) is the Nicolet (Thermo Nicolet, 2012) (fig. 5). The Nicolet hyperspectral sensor collects data in either a directional hemispherical reflectance (DHR) mode or in an attenuated total reflectance (ATR) mode. Both methods produce spectral signatures in the thermal region that are sensitive to the structural components of leaves, such as cuticles and cell walls (Ribeiro da Luz and Crowley, 2007).

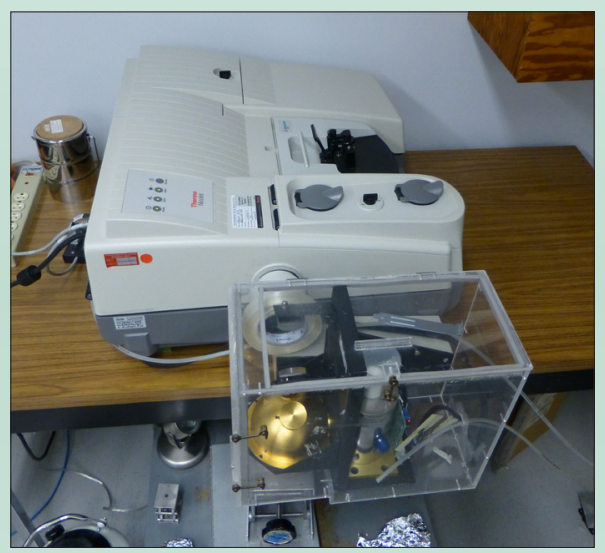

Figure 5. The Thermo Nicolet Nexus 670 FT-IR spectrometer (Thermo Nicolet, Inc., 2012).

\section{Summary}

The consequences of climate and land use and land cover change, agricultural productivity, contaminants in the environment, and invasive species are all contemporary environmental issues that confront us today and that can be effectively and efficiently studied through the use of remote sensing science. Through programs such as Landsat, the USGS-coordinated National Aerial Photography Program (NAPP), and many others, remote sensing has been a fundamental part of the USGS science mission. This research seeks to ensure that remote sensing science is applied to new, emerging environmental issues such as phytoremediation, hazardous waste monitoring, and emergency response. In addition to continuing the long and productive history of applied USGS remote sensing, this research also focuses on advances in remote sensing technology itself. Research in laboratory and imaging spectroscopy is creating a new level of remote sensing science with the ability to separate energy into very narrow wavelengths and measure the interaction of those narrow wavelengths with earth surface materials. Significant potential exists to improve the monitoring of hazardous waste fate and transport, to identify specific plants species and their chemical fingerprints, to better understand plant processes such as carbon sequestration, and to identify invasive and nuisance species. Through the use of both advanced and applied remote sensing tools, this research will help to address important societal and policy issues.

\section{References Cited}

Ribeiro da Luz, Beatriz, and Crowley, J.K., 2007, Spectral reflectance and emissivity features of broad leaf plants - Prospects for remote sensing in the thermal infrared $(8.0-14.0 \mu \mathrm{m})$ : Remote Sensing of the Environment, v. 109, p. 393-405.

Slonecker, E.T., and Fisher, G.B., 2011, An evaluation of traditional and emerging remote sensing technologies for the detection of fugitive contamination at selected Superfund hazardous waste sites: U.S. Geological Survey Open-File Report 2011-1050, 16 p., available only at http://pubs.usgs.gov/of/2011/1050/.

Slonecker, Terrence, Haack, Barry, and Price, Susan, 2009, Spectroscopic analysis of arsenic uptake in Pteris ferns: Remote Sensing, v. 1 , no. 4 , p. $644-675$.

Space Computer Corporation, 2012, ARCHER (Airborne Real time Cueing Hyperspectral Enhanced Reconnaissance): Space Computer Corporation Web page at $h t t p s: / / w w w$. spacecomputer.com/systems/archer.html.

Thermo Nicolet, 2012, ThermoNicolet Nexus Fully Integrated FT-IR spectrometer: Thermo Nicolet Nexusspectrometers, Web page at http://www.thermoscientific.com/ecomm/ servlet/techresource? resourceId $=88776 \&$ storeId $=11152 \&$ from $=$ search $\#$.

U.S. Geological Survey, 2012a, Landsat 7 history: Landsat missions Web page at http://landsat.usgs.gov/about_landsat7.php.

U.S. Geological Survey, 2012b, Landsat 8 (LDCM) history: Landsat missions Web page at http://landsat.usgs.gov/about_ldcm.php.

By E.T. Slonecker, G.B. Fisher, D.A. Marr, L.E. Milheim, and C.M. Roig-Silva

For further information, please contact:

E. Terrence Slonecker

Eastern Geographic Science Center

U.S. Geological Survey

521 National Center, 12201 Sunrise Valley Drive

Reston, VA 20192

703-648-4289 / tslonecker@usgs.gov

Please visit the Eastern Geographic Science Center Web page: http://egsc.usgs.gov

Any use of trade, product, or firm names in this publication is for descriptive purposes only and does not imply endorsement by the U.S. Government. 